\title{
Aquaporin 9 in rat brain after severe traumatic brain injury
}

\author{
Aquaporina 9 em cérebro de rato após traumatismo cerebral grave \\ Hui Liu', Mei Yang', Guo-ping Qiu', Fei Zhuo', Wei-hua Yu', Shan-quan Sun'1, Yun Xiu²
}

\begin{abstract}
Objective: To reveal the expression and possible roles of aquaporin 9 (AQP9) in rat brain, after severe traumatic brain injury (TBI). Methods: Brain water content (BWC), tetrazolium chloride staining, Evans blue staining, immunohistochemistry (IHC), immunofluorescence (IF), western blot, and real-time polymerase chain reaction were used. Results: The BWC reached the first and second (highest) peaks at 6 and 72 hours, and the blood brain barrier (BBB) was severely destroyed at six hours after the TBI. The worst brain ischemia occurred at 72 hours after TBI. Widespread AQP9-positive astrocytes and neurons in the hypothalamus were detected by means of IHC and IF after TBI. The abundance of AQP9 and its mRNA increased after TBI and reached two peaks at 6 and 72 hours, respectively, after TBI. Conclusions: Increased AQP9 might contribute to clearance of excess water and lactate in the early stage of TBI. Widespread AQP9-positive astrocytes might help lactate move into neurons and result in cellular brain edema in the later stage of TBI. AQP9-positive neurons suggest that AQP9 plays a role in energy balance after TBI.
\end{abstract}

Key words: aquaporin-9, traumatic brain injury, brain edema.

\section{RESUMO}

Objetivo: Revelar a expressão e os possiveis papéis da aquaporina 9 (AQP9) no cérebro de ratos após lesão cerebral traumática (LCT) grave. Métodos: Foram utilizados: determinação do conteúdo cerebral de água, corante cloreto de tetrazólio, corante azul de Evans, imunoistoquímica (IHQ), imunofluorescência (IF), western blot e PCR em tempo real. Resultados: 0 conteúdo cerebral de água alcançou o primeiro e o segundo (o mais alto) picos após 6 e 72 horas. A função da barreira hematoencefálica se mostrou muito prejudicada após 6 horas da LCT. A pior isquemia cerebral ocorreu após 72 horas da LCT. Astrócitos AQP9 positivos e neurônios no hipotálamo foram detectados difusamente pela IHQ e IF após LCT. A abundância de AQP9 e de sua mRNA aumentou após LCT e alcançou dois picos após 6 e 72 horas, respectivamente, da LCT. Conclusões: AQP9 aumentada pode contribuir para a eliminação de água e lactato em excesso na fase precoce da LCT. Astrócitos difusamente localizados AQP9 positivos podem ajudar a entrada do lactato nos neurônios, promovendo edema cerebral celular na fase tardia da LCT. Neurônios AQP9 positivos sugerem que AQP9 tem um papel no equilíbrio energético após LCT.

Palavras-Chave: aquaporina-9, lesão traumática cerebral, edema cerebral.

Predominantly caused by motor vehicle accidents, the traumatic brain injury(TBI) is the leading cause of death and severe disability among people under the age of 45 in Western industrialized countries ${ }^{1}$. Almost all patients suffer from severe disorder of energy metabolism ${ }^{2}$, ionic dysfunction ${ }^{3}$, and water homeostasis ${ }^{4}$ after TBI. Experimental evidences indicate that aquaporin 9 (AQP9), which is one member of the water channel family in brain, can facilitate the flow of water and permeate glycerol, monocarboxylates, and urea through the plasma membrane and it is involved in water homeostasis and neuronal energy metabolism in brain ${ }^{5}$. In brain ischemia models, the studies show that AQP9 may be a helper in the regulation of postischemic edema 6 . Yet, as far as we know, little is known about AQP9 in brain after TBI. The present study was performed to study whether brain AQP9 expression is altered and what are the possible roles of AQP9 in brain after TBI.

\section{METHODS}

\section{Experimental animal}

This study had an ethical approval by the Ethics Committee of Chongqing Medical University (CQMU). A total of 480 adult male Sprague Dawley rats supplied by the Experimental

${ }^{1}$ Institute of Neuroscience, Chongqing Medical University, Chongqing, China;

${ }^{2}$ Institute of Life Science, Chongqing Medical University, Chongqing, China.

Correspondence: Shan-quan Sun; Institute of Neuroscience, Chongqing Medical University; 400016 Chongqing - China; E-mail:19659179@qq.com

Support: This research was supported by the National Natural Science Foundation of China (No. 30470608 and 81000566$)$, Ph.D. Programs Foundation of

Ministry of Education of China for New Teacher (No. 20105503120009) and Chongqing Natural Science Foundation (cstc2011jjA10093).

Conflict of interest: There is no conflict of interest to declare.

Received 21 July 2011; Received in final form 17 November 2011; Accepted 25 November 2011 
Animal Center of CQMU (certification: 2401115), weighing $(250 \pm 50 \mathrm{~g})$ was selected for this study. All rats were raised in individually ventilated cages, with abundance water and food, in a warm, dark and quiet room. They were well anesthetized by an intraperitoneal injection (IP) of chloral hydrate (350 mg/kg) before surgery, penicillin (PNC) was applied to their wounds and they were given PNC (200,000 UI/kg, IP) and buprenorphine $(0.25 \mathrm{mg} / \mathrm{kg}$, per OS) after operation. The animals were randomly divided into Control Group $(\mathrm{n}=240)$ and TBI Group $(\mathrm{n}=240)$. Five rats were used in each method at each time point in every group. The tissue samples were collected at 1, 3, 6, 12, 24, 48, 72 hours and one week.

\section{Model establishment}

According to the methods of Feeney ${ }^{7}$, a craniectomy was performed on the skull over the right parietal cortex, leaving the dura intact. The $40 \mathrm{~g}$ falling weight dropped from $40 \mathrm{~cm}$ high to induce severe brain injury. The operation to the Control Group was the same as TBI Group, with the exception of the falling weight dropped onto the rat's head.

\section{Brain water content}

Rat brains were removed and weighed immediately after dissection (wet weight) and then dried in a vacuum oven at $120^{\circ} \mathrm{C}$ for 48 hours. The dried brain was re-weighted. The percentage of the water content was calculated as ([wet weight-dry weight] $/$ wet weight) $\times 100 \%$.

\section{Evans blue dye extravasation method}

The rats were anesthetized and Evans blue ( $2 \%$ in saline; $2 \mathrm{~mL} / \mathrm{kg}$ ) was intravenously administered by internal carotid vein one hour before rats were sacrificed. The rats were perfused transcardially with saline until the fluid from the right atrium became colorless. Rat brains were removed, weighed, and homogenized. $4 \mathrm{~mL}$ of $99.5 \%$ formamide per gram of tissue were added and placed on a shaker for 48 hours. Supernatants were collected and measured with a spectrophotometer at $620 \mathrm{~nm}$ and they were compared with a standard curve. The results were expressed as micrograms of albumin-Evans blue/milligram of brain tissue.

\section{Triphenyl tetrazolium chloride staining}

Rats were anesthetized and sacrificed. The brains were rapidly removed and sliced coronally at 2-mm intervals. All slices were incubated in 2\% 2,3,5-triphenyltetrazolium chloride (TTC) (TaKaRa, China) at $37^{\circ} \mathrm{C}$ for 20 minutes, then they were fixed in $4 \%$ paraformaldehyde solution for 24 hours.

\section{Reverse transcription real-time PCR}

Rat right brain cortices were divided and total RNA was isolated using tissue/cell RNA mini kit. The cDNAs were generated from $1 \mu \mathrm{g}$ of total RNA by superscript II RNase H-reverse transcriptase with Oligo(dT) primer. Quantity of AQP9mRNA levels was done by real time PCR, using Taqman probe. The primer pairs (Invitrogen) were given in Table 1.

The $\beta$-actin primer sets were included as house-keeping control genes. Reactions were carried out in $20 \mu \mathrm{L}$ volumes consisting of Premix Ex Taq (2x) $10 \mu$ L, PCR Forward Primer $(10 \mu \mathrm{m})$ at $0.4 \mu \mathrm{L}$, PCR Reverse Primer $(10 \mu \mathrm{m})$ at $0.4 \mu \mathrm{L}$, Taqman probe $(20 \mu \mathrm{m})$ at $0.8 \mu \mathrm{L}$, Rox reference dye (50x) at $0.4 \mu \mathrm{L}, \mathrm{cDNA}$ at $2 \mu \mathrm{L}$ and ddH2O at $6 \mu \mathrm{L}$ (TaKaRa, China). Each run consisted of serial dilution (10x) of standard preparation and rat cDNA samples to generate a standard curve. In each reaction, $2 \mu \mathrm{L}$ cDNA was amplified. The amplification program was as follows: pre-incubation at $95^{\circ} \mathrm{C}$ for ten seconds, fast start polymerase action at $95^{\circ} \mathrm{C}$ for five seconds, followed by $60^{\circ} \mathrm{C}$ for 31 seconds. Taqman probe fluorescence was acquired at $60^{\circ} \mathrm{C}$ in each amplification cycle. Changes in AQP9 mRNA expression were examined with ABI7000 Sequence Detection System (Perkin Elmer, USA). A standard curve was used to extrapolate the copy number of target cDNA in rat brain.

\section{Western blot}

The rat right brain cortices were divided and homogenized into ice-cold lysis buffer (P0013, Beyotime, China) for 15 minutes; they were centrifuged at $12,000 \mathrm{rpm}$ at $4^{\circ} \mathrm{C}$ for 10 minutes; collected the supernatant and added PMSF to the final concentration $(1 \mathrm{mmol} / \mathrm{L}) .30 \mu \mathrm{L}$ of protein and $7 \mu \mathrm{L}$ $5 \times$ buffer were boiled for five minutes and separated by SDS/ PAGE, then transferred in 55 minutes to PVDF membranes. The membranes were blocked with $5 \%$ non-fat dried milk in $0.01 \mathrm{M}$ PBS for two hours, probed with anti-AQP9 antibody (1:300) and $\beta$-actin antibody (1:500, Santa Cruz) overnight at $4^{\circ} \mathrm{C}$. The blots were incubated with horse radish peroxidase conjugated secondary antibody (1:10000 for $\beta$-actin, 1:500 for $\mathrm{AQP9}$, Santa Cruz) for four hours and they were developed in chemiluminescent substrate (Pierce, USA). The bands were quantified by gel densitometry (Bio-Rad, Hercules, USA). Results were expressed as AQP9/ $\beta$-actin.

\section{Immunohistochemistry and Immunofluorescence}

Anesthetized rats were perfused transcardially with $4 \%$ paraformaldehyde in $0.01 \mathrm{M}$ PBS. Brains were removed. The frozen serial coronal sections $(10 \mu \mathrm{m})$ were sliced. The

Table 1. Primer pairs used I reverse transcription real time polymerase chain reaction.

\begin{tabular}{ccccc}
\multicolumn{2}{c}{ Forward primers } & Reverse primers & TaqMan-probe \\
\hline AQP9 & 5'-tcccaggctcttcactgca-3' & 5'-acccacgacaggtatccacc-3' & 5'-fttgacctcaacacagttggp-3' \\
$\beta$-actin & 5'-ccctggctcctagcaccat-3' & 5'-cacagagtacttgcgctcagga-3' & 5'-faagatcaagatcattgctcp-3' \\
\hline
\end{tabular}

AQP9: aquaporin-9. 
sections were blocked in 0.01M PBS, containing $10 \%$ horse serum for six hours at $4^{\circ} \mathrm{C}$, and incubated with primary antibodies for one day at $4^{\circ} \mathrm{C}$, then with secondary antibodies overnight at $4^{\circ} \mathrm{C}$. The antibodies can be seen in Table 2 . Finally, all sections were mounted by $50 \%$ glycerin PBS and imaging in a confocal scanning microscope (Leica TCS SP2, Wetzlar, Germany).

For immunohistochemistry, according to the instructions of the manufacture (SAP-9100, Zhong Shan Golden Bridge), the sections were incubated with solution A (1\% goat serum) for one hour at room temperature (RT), then with anti-AQP9 antibody (1:300) in Tris buffered saline plus 1\% bovine serum albumin overnight at $4^{\circ} \mathrm{C}$. Being rinsed, the sections were incubated with solution B (secondary goat anti-rabbit IgG biotinylated antibody) for two hours at RT and C (incubated in streptavidin-horseradish-peroxidase complexes) for one hour at RT step by step and developed in BCIP/NBT (Santa Cruz), finally, they were mounted by hydrosol and imaged under microscope.

\section{Statistical analysis}

All statistics were performed using the SPSS 11.0 software package (Chicago, IL, USA). The level of AQP9 was expressed as means \pm standard deviation (SD). Differences between TBI and Control Groups were first compared using analysis of variance (one-way ANOVA). Thereafter, data were analyzed with independent samples $t$-test. All reported p-values were two-sided, and a value of $\mathrm{p}<0.05$ was considered statistically significant.

\section{RESULTS}

\section{Brain water content}

Brain water content was increased obviously at three hours and reached the first peak at the sixth hour $(\mathrm{p}<0.05)$. Following a slight decrease at the $12^{\text {th }}$ hour, it increased gradually and reached the highest point at 72 hours $(\mathrm{p}<0.05)$. Until one week, it still remained higher than normal. However, there was no obvious change in the Control Group (Fig 1A).

\section{Brain Evans blue content}

The concentration of Evans blue (EB) was rapidly increased after one hour and reached a maximal level at the sixth hour after TBI. Then, it decreased gradually, 72 hours later it had no obvious difference to the Control Group (Fig 1B).

\section{Extent of cerebral ischemia}

TTC stain showed that no obvious ischemic focus was noticed in one to six hours. The ischemic tissue surrounding the injured core was increased gradually after 24 hours and reached the peak at 72 hours after TBI (Fig 1E).

\section{The expression of AQP9 mRNA}

The expression of AQP9 mRNA in the Control Group was at a low level and no obvious change was found. In the TBI Group, it increased at the third hour and reached the first peak in six hours, then it slightly decreased after 12 hours, but it was still higher than normal, gradually it increased and reached the highest point at 48 to 72 hours until one week it was still higher than normal (Fig 1C).

\section{The abundance of AQP9 protein}

Western blot showed that in the TBI Group AQP9 expression was not obviously changed in one hour, however it was markedly increased at three hours and reached the first peak at the sixth hour, following a slight decrease that was still higher than normal at the $12^{\text {th }}$ hour. It gradually increased and reached the highest point at 48 to 72 hours until one week it was still higher than normal. However, the obvious change of AQP9 expression was not observed in the Control Group (Fig 1D).

\section{The expression of AQP9}

Immunohistochemistry and immunofluorescence showed AQP9 expressed in astrocytes at very low level in normal rats. AQP9 expression was also at a low level in one hour after TBI in rat brains and obviously increased after three hours in astrocytes of hippocampus, dentate gyrus, and brain tissues surrounding ventricle and subarachnoid space, also in blood endothelium near the optic chiasma and subfornical organ gliocytes (Fig 2). It reached the first peak at the sixth hour. Following a slightly decrease at 12 hours, the expression of AQP9 increased gradually with time and reached the highest point at 48 to 72 hours after TBI (Fig 2 ). Until one week, it was still higher than normal. After three hours, AQP9 immunoreactivity was also observed in neurons in hypothalamus, increasing with time and reaching the peak at 48 to 72 hours (Fig 3). In hippocampus, the slight expression of AQP9 in neurons was also observed after six hours, even at 72 hours, it was not very strong. A significant change of AQP9 expression was not found in the Control Group.

Table 2. Antibodies used in immunohistochemistry and immunofluorescence reactions.

$\begin{array}{cc}\text { Table 2. Antibodies used in immunohistochemistry and immunofluorescence reactions. } & \text { Secondary antibody } \\ \text { Primary antibody } & \text { FITC-labeled goat anti- rabbit lgG, 1:100, Santa Cruz } \\ \text { Anti-AQP9, Rabbit, 1:300, Alpha Diagnostic International } & \text { Cy5-labeled donkey anti-Goat IgG, 1:200, millipore } \\ \text { Anti-GFAP, Goat, 1:400, Santa Cruz } & \text { TRITC-labeled rabbit anti-mouse IgG, 1:200, Santa Cruz } \\ \text { Anti-NeuN, Mouse, 1:400, Chemicon }\end{array}$

AQP9: aquaporin-9; GFAP: glial fibrillary acid protein. 

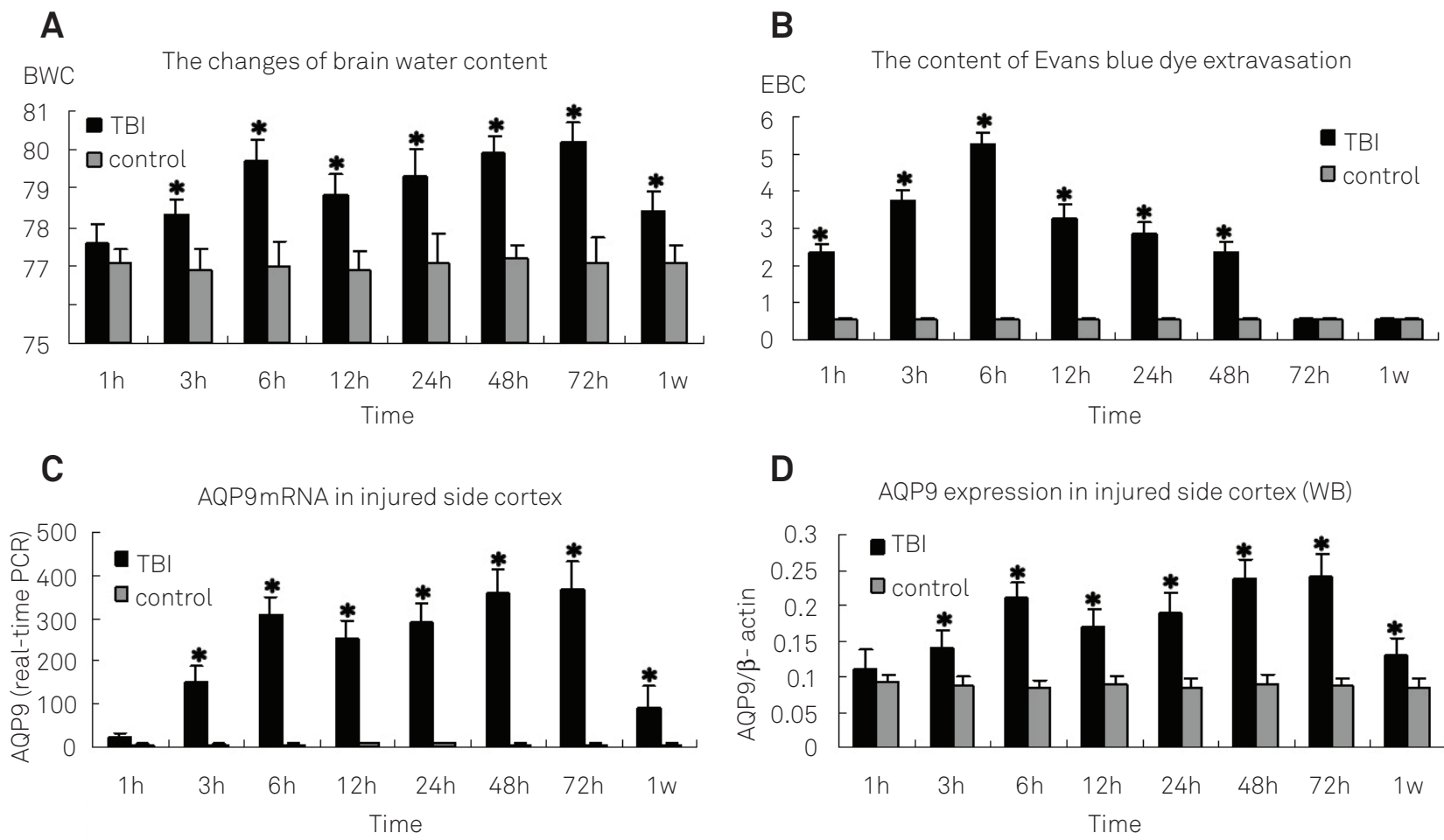

D

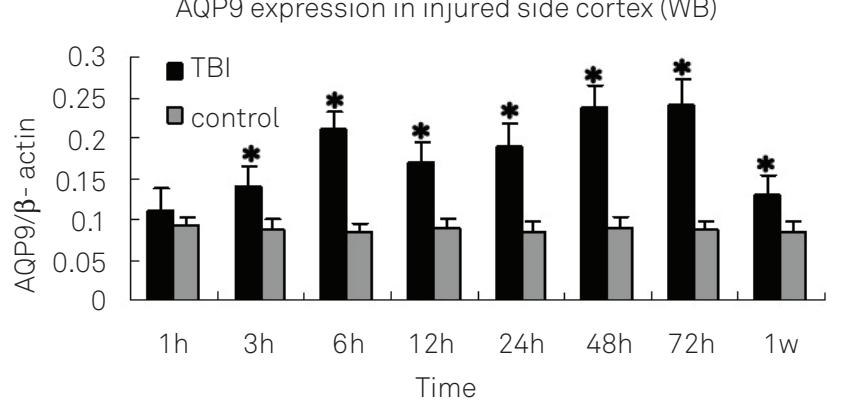

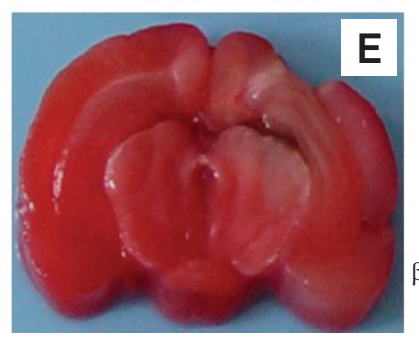

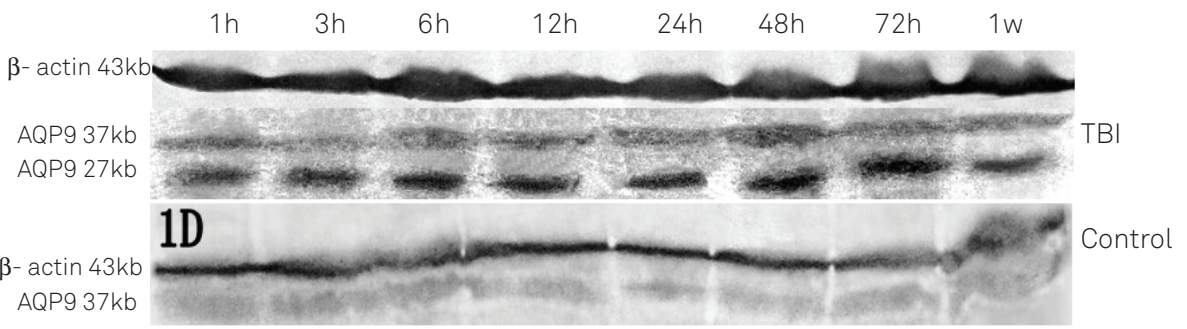

*:Obvious difference in TBI Group compared with the Control Group ( $p>0.05)$.

Fig 1. (A) The changes of brain water content; (B) The content of Evans blue dye extravasation; (C) Aquaporin-9 (AQP9) mRNA expression in injured side cortex showed by real time polymerase chain reaction; (D) AQP9 expression in injured side cortex showed by western-blot; (E) The badly brain ischemic at 72 hours after traumatic brain injury (TBI) showed by 2,3,5triphenyltetrazolium chloride staining.

\section{DISCUSSION}

AQP9 is a member of the aquaporins family, known as water channel proteins, which are small, hydrophobic, integral membrane proteins and expressed widely in animals and plants. AQP9 has the specific feature of broad range permeability, such as water, urea, glycerol, mannitol, sorbitol, purines (adenine), pyrimidines (uracil and chemotherapeutic agent 5-fluorouracil), monocarboxylates (lactate and betahydroxybutyrate), and ammonia ${ }^{8}$. In the rodent brain, AQP9 is distributed in three cell types: glial (tanycytes and astrocytes), catecholaminergic neurons and endothelial cells of sub-pial blood vessels ${ }^{4-6,8}$. It is concerned with water homeostasis, osmotic regulation, and energy metabolism in brain ${ }^{8}$.

TBI is a very common disease with metabolic disorders of water, electrolyte, and energy. According to the differences of pathophysiological processes, TBI can be divided into primary and secondary traumatic brain injury. The former, usually in the early stage of TBI, is the result of mechanical forces producing tissue deformation at the moment of injury. The latter, usually in the later stage of TBI, occurs as a complication of the primary brain injury and includes ischemic, hypoxic damage, and cerebral welling ${ }^{1}$.

In the early stage of TBI ( 1 to 12 hours), due to the damaged brain tissue and badly impaired BBB, the mass in blood, like blood cells, plasma protein, plasma, electrolytes and so on, flowed into intercellular space and caused the increase of intercellular fluid, change of osmotic pressure, and disorder of electrolyte balance. Our study found that AQP9 protein and mRNA expression increased at three hours and reached the first peak at six hours, then they decreased slightly at the $12^{\text {th }}$ hour. This change was in accordance with the one of the brain edema showed by brain water content (BWC). Although in this stage BBB was severely destructed, the brain edema was not the worst compared with the edema in the later stage of TBI. Interestingly, the distribution of AQP9 was expanded, which was observed in cerebrospinal fluid contacting interface, such as surrounding ventricle 


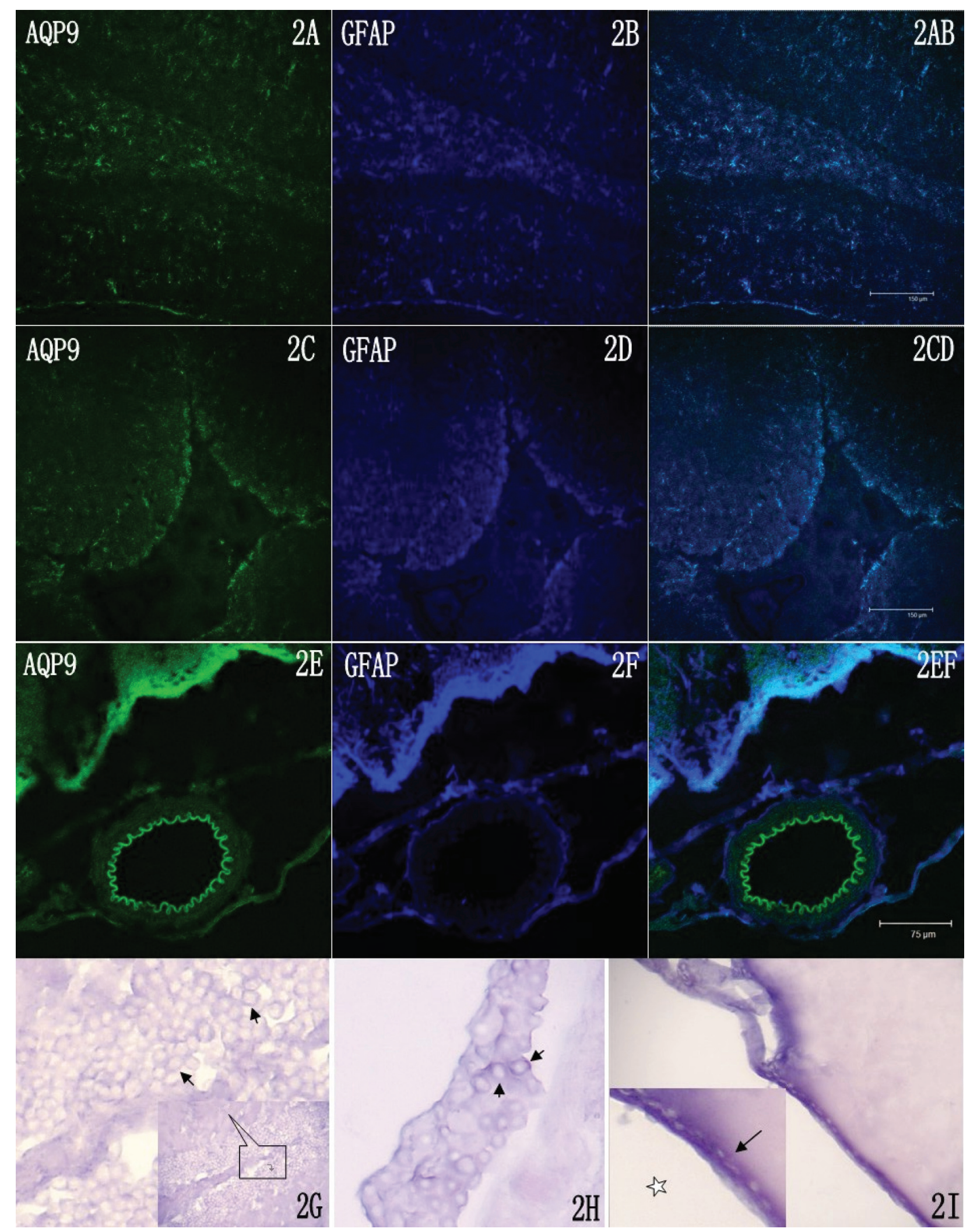

Fig 2. The increased aquaporin-9 (AQP9) immunoreactivity (green), glial fibrillary acid protein (GFAP)-labeled astrocytes (blue) and the combined double-labeled image in hippocampus at three hours after traumatic brain injury (TBI) are respectively shown in 2A, 2B, and $2 A B(\times 200)$. The increased AQP9 immunoreactivity (green) surrounding the third ventriculus tissue at six hours after TBI, the GFAP-labeled astrocytes (blue) and the combined double-labeled image are respectively shown in 2C, 2D and 2CD (×200). The increased AQP9 immunoreactivity (green) in pavimentum cerebri astrocytes and blood endothelium, the GFAP-labeled astrocytes (blue) and the combined double-labeled image at 72 hours after TBI are respectively shown in 2E, 2Fand 2EF ( $\times 200)$. AQP9 positive cells in hippocampus at three hours (2G, $\times 400)$, in choroid plexus at 48 hours $(2 \mathrm{H}, \times 400)$ and in cerebral pia mater at 48 hours $(21, \times 400)$ after TBI are showed by immunohistochemistry. $\uparrow:$ AQP9 positive cells. 


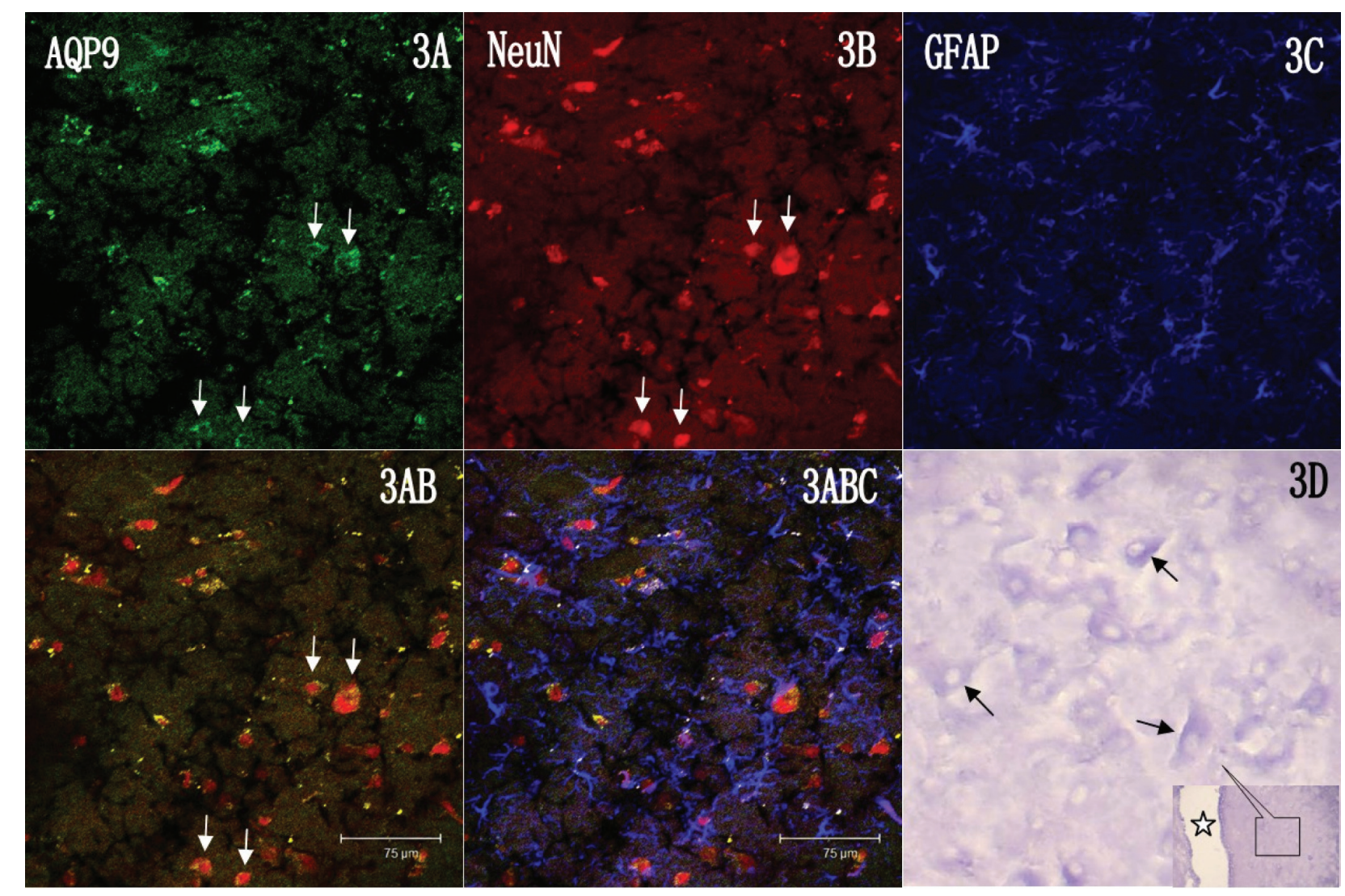

Fig 3. The increased aquaporin-9 (AQP9) immunoreactivity (green), Anti-NeuN-positive neurons and glial fibrillary acid protein (GFAP)-positive astrocytes in hypothalamus at 48 hours after traumatic brain injury (TBI) are respectively shown in 3A, 3B and 3C; $3 A B(\times 400)$ is the combined image of $3 A$ and $3 B$; $3 A B C(\times 400)$ is the combined image of $3 A$, 3B and $3 C$. AQP9 positive neurons in hypothalamus at 24 hours after TBI is shown in 3D(×400). $\uparrow$ : AQP9 positive neurons, $\vec{z}$ : The third ventricle.

and subpial tissue near the optic chiasma in pavimentum cerebri in this stage.

These results suggested that AQP9 in these areas might contribute to the clearance of the excess water in intercellular space at this stage, similar to the roles of AQP49. Additionally, the obvious increase of AQP9 immunoreactivity was also detected in astrocytes of hippocampus and dentate gyrus after TBI. This finding was in accordance with Hwang's research, which showed that AQP9 expression was induced in hippocampus 6 and 12 hours after global ischemia in region of the gerbil ${ }^{10}$. Schurr's presumed that the AQP9 expression could favor lactate and glycerol clearance from the extracellular space during ischemia ${ }^{11}$. Ischemia was one of the main pathologic processes of TBI in the early stage. Therefore, in this stage the increased expression of AQP9 might indicate its involvement in the clearance of lactate and glycerol caused by ischemia after TBI in extracellular space.

In the later stage of TBI (after 24 hours), brain damage was related to many factors, such as inflammatory response, edema formation, infiltration of peripheral blood cells, nitric oxide and nitric-oxide synthas, oxygen radicals, excess ions, and so on. These factors were thought to exacerbate the injury following TBI and could induce brain hypoxia and ischemia, then leading to energy supply deficiency. Our experiment found that the brain ischemia got worse with time and the worst one was observed at 72 hours after TBI, which was showed by TTC staining. In this stage, aerobic metabolism could be inhibited and anaerobic glycolysis was active, producing abundant lactic acid.

Magistretti et al. ${ }^{12}$ assumed a "lactate shuttle" model, where glucose was transformed by the astrocytes into lactate and diffused from astrocytes to neurons using the monocarboxylate transporters (MCTs). Tsukaguchi et al. ${ }^{13}$ found that AQP9 permeability to lactate increased four-fold when the $\mathrm{pH}$ decreased to 5.5. Recent data suggested AQP9 could facilitate the reuptake of lactate and glycerol, which could then be used as energetic substrates and was involved in the lactate movement between astrocytes and neurons that could use lactate as energetic substrates ${ }^{14}$. Lactate seemed to facilitate the recovery of neurons after ischemic insults ${ }^{11}$. Our experiment also found AQP9 immunoreactivity in astrocytes in many parts of brain area, such as hippocampus, dentate gyrus, brain cortex, thalamus, caudate nucleus, hypothalamus in later stage of TBI. Meanwhile, western blot and PCR showed that the expression of AQP9 protein and mRNA increased from 24 hours and reached the peak at 48 to 72 hours. The widely-spread AQP9-positive astrocytes in later stage of TBI might help the lactate move from astrocytes to neurons, contributing to neuron protection. Additionally, the move of lactate and glycerol into astrocytes was likely accompanied 
by a rapid water flow involving AQP9 ${ }^{14}$, thus a badly cellular brain edema was observed in our study at this stage. Moreover, AQP9 expression was changed accordingly to the development of the brain edema in this stage. Therefore, AQP9 might also contribute to the formation of cellular brain edema in the later stage of TBI.

AQP9 was expressed in neurons of hypothalamus and increased slowly and gradually by time throughout nearly all the stages after TBI (at three and after three hours). A very weak expression of AQP9 in neurons in hippocampus was also observed by immunofluorescence after three hours. It was similar with that after a metabolic stress, AQP9 expression was induced in pyramidal neurons, which did not express this channel in physiological conditions ${ }^{10}$. Up to date, findings of many experiments under many pathological situations in brain about AQP9-positive neurons suggested AQP9 plays an active role in energy balance as a glycerol-lactate-channel in neuron ${ }^{8,15,16}$. Our outcomes also suggested AQP9 might be involved in the energy metabolism of neurons after TBI.

In conclusion, this study indicated that AQP9 expression increased in different stages after TBI. The increased AQP9 might contribute to clearance of excess water, lactate and glycerol in extracellular space in early stage of TBI. The widely-spread AQP9-positive astrocytes in later stage of TBI might help the lactate move from astrocytes to neurons and protect neurons. In addition, AQP9 could also contribute to the formation of cellular edema in brain after TBI. As it was seen, AQP9-positive neurons were observed after three hours, TBI suggested AQP9 might play a role in energy balance as a glycerol-lactate-channel in neuron. The regulation mechanisms of the changed AQP9 expression and the exact roles of AQP9 in brain after TBI still need further studies.

\section{References}

1. Finnie JW, Blumbergs PC. Traumatic brain injury. Vet Pathol 2002;39:679-689.

2. Verweij BH, Amelink GJ, Muizelaar JP. Current concepts of cerebral oxygen transport and energy metabolism after severe traumatic brain injury. Prog Brain Res 2007;161:111-124.

3. Marmarou A. A review of progress in understanding the pathophysiology and treatment of brain edema. Neurosug Focus 2007;22:1-10.

4. Unterberg AW, Stover J, Kress B, Kiening KL. Edema and brain trauma. Neuroscience 2004;129:1021-1029.

5. Badaut J, Petit JM, Brunet JF, Magistretti PJ, Charriaut-Marlangue C, Regli L. Distribution of Aquaporin 9 in the adult rat brain: preferential expression in catecholaminergic neurons and in glial cells. Neuroscience 2004;128:27-38.

6. Ribeiro MC, Hirt L, Bogousslavsky J, Regli L, Badaut J. Time course of aquaporin expression after transient focal cerebral ischemia in mice. J Neurosci Res 2006;83:1231-1240.

7. Feeney DM, Boyeson MG, Linn RT, Murray HM, Dail WG. Responses to cortical injury: I. Methodlogy and local effects of contusions in the rat. Brain Res 1981;211:67-77.

8. Badaut J. Aquaglyceroporin 9 in brain pathologies. Neuroscience 2010;168:1047-1057.
9. Verkman AS. More than just water channels: unexpected cellular roles of aquaporins. J Cell Sci 2005;118:3225-3232.

10. Hwang IK, Yoo KY, Li H, et al. Aquaporin 9 changes in pyramidal cells before and is expressed in astrocytes after delayed neuronal death in the ischemic hippocampal CA1 region of the gerbil. J Neurosci Res 2007;85:2470-2479.

11. Schurr A. Lactate, glucose and energy metabolism in the ischemic brain. Int J Mol Med 2002;10:131-136.

12. Magistretti PJ, Pellerin L. Cellular mechanisms of brain energy metabolism and their relevance to functional brain imaging. Philos Trans R Soc Lond B Biol Sci 1999;354:1155-1163.

13. Tsukaguchi H, Shayakul C, Berger UV, et al. Molecular characterization of a broad selectivity neutral solute channel. J Biol Chem 1998;273:24737-24743

14. Badaut J, Regli L. Distribution and possible roles of aquaporin 9 in the brain. Neuroscience 2004;129:971-981.

15. Badaut J, Brunet JF, Petit JM, Guérin CF, Magistretti PJ, Regli L. Induction of brain aquaporin 9 (AQP9) in catecholaminergic neurons in diabetic rats. Brain Res 2008;1188:17-24.

16. Dibas A, Yang MH, Bobich J, Yorio T. Stress-induced changes in neuronal Aquaporin-9 (AQP9) in a retinal ganglion cell-line. Pharmacol Res 2007;55:378-384. 